\title{
INTERPRETACIÓN E IDEOLOGÍA CONSTITUCIONAL. UNA PROPUESTA DE ESTUDIO A LAS DECISIONES EN MÉXICO*
}

\author{
Luis Eusebio Alberto Avendaño González** \\ Jorge Serrano Ceballos** \\ Recibido: Febrero 1 de 2017 \\ Aprobado: Abril 7 de 2017
}

\begin{abstract}
RESUMEN
Las decisiones judiciales transitan no solo por el binomio interpretaciónaplicación del derecho, sino de igual forma por la ideología que subyace a los operadores mismos. Dotar de sentido a las normas constitucionales, transita no solo por desentrañar, sino por asignarles un significado ideológico, jurídico y político a la norma constitucional, circunstancia que en México recae en los ministros que integran el Pleno de la Suprema Corte de Justicia.
\end{abstract}

Palabras clave: Ideología, interpretación, Poder judicial federal en México

\section{INTERPRETATION AND CONSTITUTIONAL IDEOLOGY. A PROPOSAL FOR A STUDY OF JUDICIAL DECISIONS IN MEXICO}

\begin{abstract}
Judicial decisions do not only go through the binomial interpretationapplication of the law, but also through the ideology that is hidden in the

* El presente estudio rescata algunas líneas de trabajo respecto al manuscrito publicado en la obra colectiva Ética y justicia. Reflexiones y planteamientos intemporales coordinada por el Dr. Juan Ricardo Jiménez Gómez y publicada por Miguel Ángel Porrúa editores en el año 2014.

** Doctor en Derecho. Profesor de tiempo completo en la Facultad de Derecho de la Universidad Autónoma de Querétaro. Miembro del Sistema Nacional de Investigadores, nivel I. CONACyT.

*** Doctor en en Derecho. Profesor de tiempo completo en la Facultad de Derecho de la Universidad Autónoma de Querétaro. Miembro del PRODEP.
\end{abstract}


legal operators themselves. To make sense of constitutional norms passes not only through unravelling, but also through assigning an ideological, legal and political meaning to the constitutional norm, a circumstance that in Mexico lies with the ministers who integrate the Plenum of the Supreme Court.

Key words: Ideology, interpretation, federal judiciary in Mexico.

\section{INTERPRETAÇÃO E IDEOLOGIA CONSTITUCIONAL UMA PROPOSTÁ DE ESTUDO ÁS DECISÕES NO MÉXICO}

\section{RESUMO}

As decisões judiciais passam não só pelo binômio interpretaçãoaplicação do direito, mas também pela ideologia por trás dos próprios operadores. Fazer sentido das normas constitucionais, passa não só para desvendar, mas atribuindo um significado ideológico, jurídico e político à norma constitucional, circunstância que no México cabe aos ministros que compõem o Plenário do Supremo Tribunal de Justiça.

Palavras-chave: Ideologia, Interpretação, Poder judicial federal no México.

\section{INTRODUCCIÓN}

La integración el Pleno de la Suprema Corte de Justicia en México, no solo es consecuencia de un riguroso proceso de selección, sino también de acuerdos políticos entre los partidos que representan a la Cámara de Senadores. El sistema político-jurídico en México, históricamente representó el autoritarismo y cacicazgos sectoriales -un partido político único, control de las organizaciones sindicales y empresariales, de los medios de comunicación, la definición de diputados, senadores, gobernadores-, lo cual confería de facto facultades metaconstitucionales al Ejecutivo federal (Cossío, 1996, p. 1). Lo anterior, trajo como consecuencia que el Poder Judicial Federal ejerciera también una ideología fundada exclusivamente en el discurso revolucionario.

A partir de la reforma constitucional de 1994, la conformación del Pleno de la Suprema Corte de Justicia de la Nación ha variado y permitido con ello la designación de ministros tanto 'internos' como 'externos', es decir, aquellos integrantes de carrera del propio poder judicial federal, así 40 
como la de aquellos que no lo son. En el mismo sentido se puede definir tanto a ministros 'conservadores' y 'liberales', calificados así a partir del sentido de sus determinaciones. A lo anterior se suma el hecho de que las decisiones de los jueces transitan no solo por la aplicación del derecho, sino de igual forma por la ideología personal -religiosa, política y personal- que subyace a cada Ministra o Ministro, todo lo cual incide en la interpretación constitucional.

Por lo anterior, constituye uno de los objetivos del presente estudio distinguir la ideología en la aplicación de la justicia que ejerce el máximo tribunal en México, ya que los actores judiciales en la interpretación constitucional dotan de sentido y no solo desentrañan la norma constitucional. Suponer que las ministras y ministros son totalmente asépticos en la determinación de sus resoluciones es negar su protagonismo en el tránsito hacia un nuevo diseño del estado constitucional de derecho.

La hipótesis del presente estudio es: i) señalar que las Ministras y Ministros que integran el Pleno de la Suprema Corte de Justicia modulan la interpretación constitucional, fundada particularmente en dos supuestos: a) el mecanismo de integración, y b) la ideología que define el sentido de sus determinaciones aplicado a casos relevantes. La metodología consiste en un estudio descriptivo y sistemático de las premisas de la interpretación constitucional en las resoluciones emitidas.

\section{LA INTEGRACIÓN DEL PLENO DE LA CORTE EN MÉXICO}

En términos del artículo 49 de la Constitución Política de los Estados Unidos Mexicanos el 'poder' es único, sin embargo, se divide para su ejercicio en Ejecutivo, Legislativo y Judicial. Razón por la cual éste último constituye en su estructura y en el sentido de sus determinaciones un elemento también político en el ejercicio del poder público.

\section{a) Consideraciones generales}

A partir de la promulgación de la Constitución federal vigente, el artículo 94 -que define la integración del Poder Judicial Federal- ha sido modificado en 12 ocasiones; lo cual permite identificar el tránsito en la integración del Pleno de la Suprema Corte de Justicia de la Nación.

El texto aprobado por el constituyente de 1917 dio a cada una de las Legislaturas Locales la atribución de nominar a un 
candidato y al Congreso de la Unión la de elegir entre ellos a los 11 que, por un plazo de cuatro años, integrarían la Corte. En 1928 por reforma constitucional se transfirió la nominación al ejecutivo y la designación al Senado; al tiempo que aumentó a 16 el número de integrantes y eliminó el plazo fijo de cuatro años en el cargo. La Corte incrementó en número de 16 a 21 (1934) y luego a 26 (1944), lo mismo que los plazos de duración en el encargo; primero se limitaron a seis años (1934) y luego se eliminó esa cláusula en 1944. El método de designación permaneció intacto hasta la reforma constitucional del Presidente Ernesto Zedillo en el año de 1994 en que la vigencia se limitó a 15 años improrrogables (Saavedra, 2012, p. 40).

Es de señalar que entre 1917 y 1994 se realizaron en promedio 2.5 designaciones por año, equivalente a una renovación media anual del $12.9 \%$ de los ministros; en los años de 1920 y 1921 no existió renovación de Ministros. La Corte a partir de 1928, se convirtió en un órgano cada vez más complejo y fragmentado hasta sumar un número total de 26 integrantes vitalicios. De 1994 a 1997 tanto la Presidencia como ambas cámaras del Congreso estuvieron controladas por el PRI, como fue el caso desde 1929. Es importante tener en cuenta que fue un gobierno controlado por el PRI el que decidió hacer la reforma de 1994. Sin embargo, en las elecciones intermedias de 1997 el PRI perdió la mayoría absoluta en la Cámara de Diputados, aunque continuó teniendo la mayoría absoluta en el Senado.

La situación política del Poder Judicial Federal hasta antes de la reforma constitucional de 1994 traía consigo definir que políticamente la Corte y el mismo Poder Judicial en general, eran una pieza más en el sistema de partido dominante que fue capaz de incorporarlos dentro de su estructura corporativa al igual que lo hizo con otros órganos de gobierno tales como los sindicatos, los campesinos, el ejército y los empresarios (Ríos, 2004, p.11).

\section{b) La reforma constitucional de 1994}

Los acontecimientos económicos, políticos y sociales que precedieron a la reforma constitucional que reconfiguró al Poder Judicial Federal de 1994 fueron complejos -el $1^{\circ}$ de enero surge el EZLN como oposición al inicio de vigencia del TLCAN, en marzo muere el candidato del partido oficial Luis Donaldo Colosio y en septiembre el ex gobernador de Guerrero y secretario general del PRI José Francisco Ruiz Massieu-. La 
reforma disolvió de facto a dicho poder originario, conformada entonces por 26 ministros, y reduciéndolo a una integración de 11 ministros, se limitó el periodo en el cargo a 15 años y se estableció una mayoría calificada de $2 / 3$ en el Senado como requisito para realizar las designaciones. Además, a las funciones con las que ya contaba el Pleno de la Corte con motivo de la reforma, se añadieron las de un 'modelo de tribunal constitucional', así como la emisión de los acuerdos 5/1999, 6/1999, 10/2000 y 4/2001, el Pleno se reservó el monopolio de la interpretación de la Constitución mediante el conocimiento en última instancia de los juicios de amparo en revisión, las controversias constitucionales y las acciones de inconstitucionalidad. De igual modo, la creación de criterios ideológicos y éticos propios a partir de la conformación de la $9^{\mathrm{a}}$. Época en criterios jurisprudenciales.

En síntesis, se crearon instrumentos eficientes de control constitucional que permiten establecer un equilibrio dentro de un sistema de frenos y contrapesos de los poderes públicos.

\section{c) Selección y designación de los Ministros}

A diferencia del proceso de Estados Unidos en cuanto a la selección de quienes habrán de integrar la Corte Suprema, -la cual carece de 'consulta' al Senado, así como requisitos definidos- el Presidente cuenta con mayor control sobre el proceso, el cual solo permite a un solo candidato y ante su no elegibilidad, tendrá que proponer a otro. La politización también está presente en el nombramiento de los Justices, y la ideología de los mismos cuenta mucho para predecir el sentido de sus fallos. Ello incluso refleja el tipo de equilibrios políticos entre republicanos y demócratas, a mayor numero de senadores de un partido, será electo un Justice más conservador o liberal.

En México, el cargo de ministro constituye el escalón más alto dentro del Poder Judicial de la Federación; para acceder a él, es necesario cumplimentar los requisitos que marca el artículo 95-constitucional:

Artículo 95. Para ser electo Ministro de la Suprema Corte de Justicia de la Nación, se necesita:

I. Ser ciudadano mexicano por nacimiento, en pleno ejercicio de sus derechos políticos y civiles.

II. Tener cuando menos treinta y cinco años cumplidos el día de la designación;

III. Poseer el día de la designación, con antigüedad mínima de diez años, título profesional de licenciado en derecho, 
expedido por autoridad o institución legalmente facultada para ello;

IV. Gozar de buena reputación y no haber sido condenado por delito que amerite pena corporal de más de un año de prisión; pero si se tratare de robo, fraude, falsificación, abuso de confianza y otro que lastime seriamente la buena fama en el concepto público, inhabilitará para el cargo, cualquiera que haya sido la pena.

V. Haber residido en el país durante los dos años anteriores al día de la designación; $y$

VI. No haber sido Secretario de Estado, Procurador General de la República o de Justicia del Distrito Federal, senador, diputado federal ni gobernador de algún Estado o Jefe del Distrito Federal, durante el año previo al día de su nombramiento.

Los nombramientos de los Ministros deberán recaer preferentemente entre aquellas personas que hayan servido con eficiencia, capacidad y probidad en la impartición de justicia o que se hayan distinguido por su honorabilidad, competencia y antecedentes profesionales en el ejercicio de la actividad jurídica (Constitución Política de los Estados Unidos Mexicanos 1917, art. 95).

Sin embargo, dicha circunstancia no siempre opera en la práctica, ya que, si bien la Constitución establece que deberá privilegiarse el ejercicio profesional, es decir, miembros 'internos' del Poder Judicial Federal, lo es también, que el artículo 96 dispone el procedimiento que apertura el ingreso de miembros 'externos' a la conformación definitiva del Pleno de la Suprema Corte de Justicia de la Nación.

Artículo 96. Para nombrar a los Ministros de la Suprema Corte de Justicia, el Presidente de la República someterá una terna a consideración del Senado, el cual, previa comparecencia de las personas propuestas, designará al Ministro que deba cubrir la vacante. La designación se hará por el voto de las dos terceras partes de los miembros del Senado presentes, dentro del improrrogable plazo de treinta días. Si el Senado no resolviere dentro de dicho plazo, ocupará el cargo de Ministro la persona que, dentro de dicha terna, designe el Presidente de la República.

En caso de que la Cámara de Senadores rechace la totalidad de la terna propuesta, el Presidente de la República someterá una nueva, en los términos del párrafo anterior. Si esta 
segunda terna fuera rechazada, ocupará el cargo la persona que dentro de dicha terna, designe el Presidente de la República (art. 96).

Las reglas de elección sólo pueden ser explicadas en el contexto político en el que se aprobó la reforma constitucional de 1994. Señalan Carlos Elizondo Mayer-Serra y Ana Laura Magaloni que el hecho de que el nombramiento de los 11 Ministros se hiciera al mismo tiempo -ya que con dicha reforma se removió a un mismo tiempo a los 26 Ministros que conformaban ese tribunal- hacia difícil, en términos políticos, que el presidente simplemente mandara 11 candidatos por separado (MayerSerra 2010, p. 37). La terna fue un mecanismo que aminoró la percepción de que el entonces presidente Zedillo conformaba una Corte a modo.

La operación de este más compacto y poderoso órgano se puso en manos de nuevos Ministros, todos ellos designados a partir de una lista de entre 18 elegibles. El 26 de enero de 1995 el Senado designó a ocho Ministros de carrera judicial 'candidatos internos' y a tres que no contaban con ella 'candidatos externos'. Esta integración permaneció sin cambios durante casi nueve años, algo sin precedentes en la historia de México. En 2003 se abrieron las primeras dos vacantes (salieron José Vicente Aguinaco Alemán y Juventino Castro y Castro), seguidas por tres que también se tenían programadas (Juan Díaz Romero, Mariano Azuela Güitrón y Genaro Góngora Pimentel) y por dos imprevistas provocadas por el fallecimiento de Ministros en funciones (Román Palacios en 2004 y Gudiño Pelayo en 2010).

Al mismo tiempo, si las cosas no salían bien, el presidente siempre podía tener la última palabra. Es decir, si en dos ocasiones el Senado rechazaba la terna, el Ejecutivo podía nombrar libremente al Ministro de su preferencia. Se trataba de conformar un nuevo tribunal con mayor legitimidad, pero, al mismo tiempo, de no renunciar de forma absoluta al control del Ejecutivo en el sistema de nombramientos.

En esos años, el partido del presidente Zedillo contaba aun con la mayoría de los votos en ambas cámaras, pero carecía de los dos tercios requeridos para ratificar el nombramiento. Había que consensar dichos nombramientos con el PAN -que era la segunda fuerza política del país-, por lo que, si bien la mayoría de los nombramientos fueron del presidente, éste tuvo que negociar algunos lugares para candidatos 
emanados del PAN. El resultado fue una Corte donde predominaban ministros vinculados con el viejo régimen y que tenían la confianza del PRI. El peso del PRI en la selección de ministros continuó en el gobierno de Fox - primer presidente de la oposición- ya que en esa administración predominaron candidatos cercanos al PRI. Con un panorama distinto al de otros países, en la configuración de la Corte no se apostó por un tribunal constitucional para la democracia, sino uno que permitiera atender los problemas de la naciente pluralidad política de la última fase del régimen autoritario. Ello explica, por qué el presidente Zedillo optó por designar principalmente Ministros que se hubiesen desempeñado como jueces por varios años. Refiere nuevamente Mayer Serna (2010) que no había razones para pensar que se requería un tribunal constitucional conformado por ministros encargados de marcar la diferencia entre un régimen político autoritario y una democracia constitucional en forma. Más bien había necesidad de mantener alguna continuidad con el pasado. Los ministros con experiencia judicial eran una apuesta razonable para lograr ese objetivo.

En este proceso de continuidad y no de ruptura con el pasado es evidente el tipo de argumentación jurídica de las sentencias de la Corte, donde los ministros ni siquiera han detectado el problema de que la mayor parte de la jurisprudencia constitucional se generó bajo las coordenadas de un sistema político autoritario y que, por tanto, se requería de una profunda revisión de lo que hoy, en un contexto democrático, deberían ser los criterios de interpretación y ética de la Constitución acorde a los nuevos paradigmas que representa el derecho.

Actualmente el proceso de selección y designación de ministros ha mostrado debilidades, ya que es cada vez más complejo y politizado. En la medida que el presidente presente ternas, el Senado puede negociar entre los candidatos propuestos. El sistema de ternas obliga a los tres candidatos a Ministro a competir entre ellos para lograr los apoyos requeridos, lo cual puede tener un efecto negativo en la fortaleza e independencia del máximo tribunal. Así, la selección de los ministros no es rigurosa, pero si en extremo politizado, lo cual hace que no se cuente con una definición clara sobre la ideología de los candidatos. Sin estas definiciones, lo que se puede esperar es que quien ocupe el puesto de ministro no sea necesariamente el que tenga los mayores méritos o refleje mejor la ideología que defienden los partidos, sino el que haya construido la mejor red de apoyos políticos, lo cual, incluso, pudiera mermar su independencia e imparcialidad. Aquí se fortalece lo previsto en las hipótesis planteadas, en el sentido de que las reglas de elección y duración de encargo tienen un efecto sobre quienes llegan a ministros y 46 
con qué expectativas. Por lo que, el método por el cual los once ministros llegan a su decisión, cualquiera que ésta sea, afecta lo que se decide.

\section{d) Conformación actual del pleno de la Corte en México}

La integración de la Corte en 1994 era de 11 ministros 10 de ellos hombres y 1 mujer-. Actualmente dicha composición en razón de género, recae en 2 mujeres y 9 hombres. Es decir, se incrementó a $18.18 \% .7$ de los 11 ministros son de carrera judicial, lo cual representa el $63.63 \%, 3$ ejercieron cargos privados y públicos antes del encargo constitucional, lo cual representa el $27.27 \%$ y por último solo el $18.18 \%$ ejerció cargos académicos antes de der nombrado Ministro.

En México, el cargo de ministro dura 15 años, la ventaja que representa que el cargo sea temporal y no vitalicio apertura el debate sobre qué tipo de Corte se necesita, dado que nuestra Corte es una institución que se diseñó en las postrimerías de un régimen autoritario. Lo anterior no omite la red de influencias internas y externa que se cosechan al cabo de los años de ejercicio constitucional. El problema no es menor, el esquema de retiro de los ministros está directamente relacionado con el ejercicio cotidiano de su independencia.

La primera Corte luego de las reformas de 1994 estableció un sistema de sustitución escalonada, concluyendo en sus funciones bajo el siguiente calendario: 30 de noviembre del 2006: Ministro Juan Díaz Romero; 30 de noviembre del 2009: Ministro Mariano Azuela Güitrón y Ministro Genaro David Góngora Pimentel; 30 de noviembre del 2012: Ministro Guillermo I. Ortiz Mayagoitia y Ministro Sergio Salvador Aguirre Anguiano; 30 de noviembre del 2015: Ministro José de Jesús Gudiño Pelayo, Ministro Juan N. Silva Meza y Ministra Olga María del Carmen Sánchez Cordero Dávila de García Villegas (Acuerdo general del pleno del Consejo De La Judicatura Federal que establece las condiciones generales de trabajo para magistrados de circuito y jueces de distrito. título ii del ingreso, ascenso y protesta constitucional)

Por último, por cuanto ve a la elección del Presidente de la Corte en términos del artículo 97 Constitucional, éste es electo por pares cada cuatro años, el cual no puede ser reelecto para el periodo inmediato posterior. Lo anterior, es un mandato acotado ya que agotado el periodo de su mandato volverá a ser un ministro más. En el mismo sentido cabe señalar que desde 1994 ninguna mujer ha ocupado el cargo de Presidenta 
de la SCJN, así como tampoco ningún ministro "externo", es decir, que no pertenezca de carrera al Poder Judicial Federal.

\section{LAJUSTICIA CONSTITUCIONAL EN MÉXICO}

El debate teórico y empírico sobre cómo se eligen a los jueces y cómo actúan a partir de 1994, se conoce como justicia por procedimiento, la cual ha demostrado que el proceso de elección de los Ministros que integran el Pleno de la Corte, así como el proceso por el cual los jueces llegan a sus decisiones, influye en el resultado y percepción social de las mismas.

A partir de ello, la ideología de los ministros en la impartición de justicia a través de las resoluciones judiciales no radican exclusivamente del contenido de las mismas y de su argumentación, sino que también están correlacionadas positivamente con la forma o proceso a través del cual los ministros llegan a ellas y de la legitimidad con la que deben tomar sus decisiones.

Dada la enorme carga laboral la Suprema Corte de Justicia opera en dos salas, además de en Pleno. Caso contrario la Corte estadounidense siempre opera en Pleno -A partir de ello, el proceso de decisión de la Corte cuenta con tres características centrales: a) Asignación de casos a partir de un sistema aleatorio, b) Publicidad del debate y deliberación entre ministros, y c) Audiencias informales privativas entre Ministros y quejosos-, ejemplo de ello en 2013, el Pleno realizó En el período comprendido del $1^{\circ}$ de diciembre de 2012 al 29 de noviembre de 2013, el Tribunal Pleno de la Suprema Corte de Justicia de la Nación celebró 104 sesiones públicas y 51 privadas. Por su parte, las Primera y Segunda Salas sesionaron en 43 y 42 ocasiones. Durante el período mencionado, ingresaron a la Suprema Corte de Justicia de la Nación, para estudio del Tribunal Pleno y de las Salas, un total de 4,775 asuntos diversos a incidentes de inejecución (1,768 asuntos), distribuidos de la siguiente forma: 4,570 (95.7\%) asuntos ingresaron al Pleno, $125(2.6 \%)$ a la Primera Sala y $80(1.7 \%)$ a la Segunda Sala. De los 4,647 asuntos egresados, diversos a incidentes de inejecución $(2,604)$, el Pleno resolvió 251 (5\%) asuntos, la Primera Sala 2,123 (46\%), y la Segunda Sala 2,273 $(49 \%)$ asuntos.

Los asuntos que son turnados al Pleno son asignados a un determinado Ministro a partir de una lista preestablecida. Dicha lista determina un orden secuencial entre ministros. El ministro al que le "toca" el asunto tiene que elaborar el proyecto de sentencia que en su momento discutirán 48 
los once ministros. A cambio de esta equidad en el número de asuntos por resolver, y la aleatoriedad en su importancia, el método de asignación inhibe o dificulta el consenso entre los ministros respecto al sentido final de la sentencia. Cuando se asigna un asunto a un ministro determinado con bases aleatorias no es relevante la posición jurídica del ministro respecto del caso a resolver. Tampoco lo es el grado de acuerdo o discrepancia que existe entre los miembros del tribunal. El ministro que proyecta la sentencia puede estar con la mayoría o estar en clara minoría. El proceso por el que se asignan los casos ni siquiera permite saber esto ex ante. Es decir, el ministro elabora su proyecto sin conocer previamente la opinión jurídica de sus compañeros de tribunal. Incluso no se circula el material entre sus pares, muchas veces éste se presenta ante el Pleno sin siquiera una lectura por parte de los ministros.

La lectura e interpretación del derecho, no resulta claro, ni univoco ni mucho menos incontrovertible. Prueba de ello son los votos concurrentes y disidentes de los propios ministros. Cada uno de los miembros del máximo tribunal tiene, ineludiblemente su propia ideología, sus prejuicios, su forma de entender el derecho, la Constitución y su manera particular de concebir y desempeñar la función de juez constitucional. En la medida en que estas divergencias ideológicas y conceptuales entre los ministros encuentren puntos de consenso y de unidad, las decisiones de la Corte tendrán mayor claridad, contundencia y grado de autoridad hacia el futuro. Las decisiones de la Corte se toman por una estrecha minoría y en donde existen varios votos concurrentes y disidentes sólo reflejan las distintas posiciones jurídicas e ideológicas de los miembros que lo integran. Una decisión constitucional dividida crea incertidumbre jurídica debido a la predictibilidad sobre lo que los ministros harán en el futuro en casos análogos.

Es necesario el consenso entre los ministros a partir del cual se diluyan discrepancias y emitir resoluciones con una sola voz, 'la voz de la Suprema Corte', dotó a dicha decisión de la contundencia política y jurídica que se requiere. Enfrentar el fenómeno de 'decisiones divididas' es más complicado dado el propio proceso de asignación de casos. Éste refleja, a su vez, la dificultad que tienen los ministros para hacerse cargo de la diferencias ideológicas, jurídicas y conceptuales que existen entre ellos.

De lo anterior, se confirma la hipótesis de que la elección de los Ministros crea un órgano de deliberación más que jurídico, ético e ideológico en el sentido de la resolución de las controversias que le son puestos de su 
conocimiento. En síntesis, la interpretación constitucional a nivel Pleno de la Corte es política e ideológica.

\section{IDEOLOGÍA E INTERPRETACIÓN CONSTITUCIONAL DE LA CORTE EN MÉXICO}

\section{a) Consideraciones generales}

La ideología aplicada al derecho mexicano se centra en la Constitución como norma y como principio. Así la Teoría Constitucional en nuestro país implica que ha de entenderse que se cuenta con un pensamiento estructurado y continuado de la Constitución, de sus elementos componentes, de la jerarquía de sus normas, de sus criterios de interpretación y de las funciones que debe cumplir respecto de las normas inferiores, primordialmente.

En el mismo sentido la teoría debe ser continuada, en la medida en que la misma haya servido para producir diversas resoluciones o, al menos, fijado la posición del tribunal a lo largo de cierto periodo (Cossío 2002, p. $82)$.

Así, podemos dividir jurídica y políticamente el discurso de la Suprema Corte de 1917 a la fecha, tomando como referencia la clasificación siguiente: 1. El periodo constitutivo (de 1917 a 1927), 2. El periodo liberal (de 1928 a 1934), 3. El periodo socialista (de 1934 a 1940), 4. El periodo estatista (de 1940 a 1994), 5. El periodo garantista (de 1994 a 2011), y 6. El periodo internacional, derivado de las reformas constitucionales en materia de Derechos Humanos y Juicio de Amparo.

Para identificar los alcances de la ética e ideología en la definición de las normas, particularmente de las normas constitucionales, describiré la ética en general. Así, los orígenes del pensamiento sistemático sobre el bien y el mal se encuentran en Grecia. El primero en denominar 'ética' a dichos cuestionamientos fue Aristóteles, quien se refería a estos asuntos como 'cuestiones sobre el ethos', esto es, cuestiones sobre el carácter (Rivero 2007,p. 13).

Platón insistía en tres aspectos que conforman la ética y que deben estar presentes cuando ésta se construye: a) para hablar de ética es necesario deliberar utilizando la razón y no los sentimientos, b) la ética implica pensar por cuenta propia sin hacer caso de lo que diga la mayoría -no es una decisión democrática-, y c) la ética requiere que se asuma un 50 
cometido fundamental: nunca ser injustos. Aristóteles a su vez, cambia su significado de costumbre a hábito. Se flexionó otra vez la vocal, se volvió a escribir con vocal doble, pero no regresó al significado original de 'guarida', sino que comenzó a significar 'carácter'. Este cambio nos indica, según Aristóteles, que el carácter tiene algo que ver con el hábito o costumbre: que el carácter se adquiere o conquista por medio del hábito o, para decirlo con palabras de hoy, mediante la disciplina. De hecho, podemos decir que el carácter moral se adquiere, a veces sin darse cuenta, por medio de costumbres, y el carácter ético se conquista, con muchos esfuerzos, por medio de las costumbres. Pero entre el eethos como carácter y el ethos como costumbre existe una relación que explica el parentesco lingüístico. La familia de significados que mencionamos alude a tres acepciones: guarida, costumbre y carácter; y por ello, en algún sentido, seguramente la ética puede ser para nosotros, hombres y mujeres del siglo XXI, una guarida, una costumbre o un carácter.

Si el significado de eethos-guarida resuena en la ética de hoy, es conveniente reflexionar acerca de quién o de qué nos salvamos en la ética. Primero, la ética nos salva de la corrupción del alma. Sócrates, el padre de la ética, enseñó con su muerte que es peor cometer el mal que recibirlo: el verdadero mal es aquel que nosotros hacemos, no el que se hace en contra nuestra. Por qué el mal que nosotros hacemos daña nuestra psique, que para Sócrates es la verdadera identidad del ser humano, es lo que somos. Por eso es peor dañar que ser dañado, y la ética nos salva de dañar, de cometer el mal: la ética nos salva a nosotros mismos, de nuestra ambición o mezquindad, de nuestras debilidades humanas; nos salva de caer, porque es menos malo - diría Sócrates en su apología- ser alcanzados por la muerte que ser alcanzados por el mal. Hay algo más valioso que la vida: la vida digna, la vida buena.

Pero también la ética es guarida por salvarnos de las inclemencias de la moral. Nacemos en una sociedad con una moral que no elegimos. Otros la eligieron y vemos la vida con mirada prestada, tomada de otros; valoramos como 'uno' valora, pensamos como 'uno' piensa y vivimos como 'uno' vive. Así, pronto aprenderemos que uno no dice esas cosas en público, uno no hace tal o cual cosa, uno debe obedecer. La ética nos salva de ser 'uno' más del montón de borreguitos buenos, y nos lleva a pensar por cuenta propia, para seguir normas propias: la ética nos salva de la moral. Es necesario estar dispuestos a ser inmorales, si se quiere ser ético. Sócrates fue un inmoral, por eso lo condenaron a muerte; no es raro encontrar individuos éticamente auténticos, que sean inmorales para la sociedad, pero lo más frecuente es encontrar aquellos que siendo 
moralmente 'buenos', son personas sin ética personal, que siguen ciertas normas 'por encima' solo para cubrir el expediente. En resumen, a través de nuestras costumbres podemos llegar a crearnos cierto carácter que acaso pueda salvarnos del mal: eso pretende la ética. Porque ethos como carácter, lo tiene cualquiera, pues cualquiera se acostumbra a ciertos hábitos a lo largo de su vida: el quid del asunto radica en si ese ethos es libre y adquirido en forma consciente, si implicó un pensar por cuenta propia o simplemente el individuo se ha dejado moldear por costumbres que ha seguido sin cuestionarse, pro costumbres que estableció la mayoría.

\section{b) Consideraciones generales en torno al sentido moral e ideológico de los Ministros}

Las normas constitucionales son normas-principio. A partir de ello, es necesario cuestionar si los jueces ¿toman decisiones políticas?, ¿son políticas sus decisiones?, o ¿debieran ser interpretadas en sentido moral? Está claro que en cierto sentido deben serlo, razón por la cual en muchos casos, la decisión de un juez recibirá la aprobación de un grupo político y el rechazo de otros. No me refiero la discrecionalidad en cuanto a seleccionar casos fáciles o casos difíciles a partir de los cuales se haga una excepción al derecho, quiero plantear el hecho de que el sentido de las resoluciones a cargo de la Corte no se limita exclusivamente a aplicar el derecho desprovisto de ponderaciones axiológicas, éticas, valorativas e incluso ideológicas. "Muchas de las decisiones producidas [por los jueces] revelan profundas divisiones y en algunas llevan la marca de un combate ideológico en bruto" (Kennedy 2010,p. 113).

Deseo plantear si los jueces deben basar sus decisiones en consideraciones políticas, de modo tal que la decisión no sólo sea la que buscan algunos grupos políticos, sino que además se funde en la creencia de que ciertos principios de moral política son correctos. Incluso algunos académicos afirman que varias de las decisiones son políticas que responden a circunstancias y hechos particulares, -ejemplo de ello el Pacto de anatocismo en 1995 que significo el rescate bancario-, por mucho que los tribunales se esfuercen por presentar los fundamentos de los fallos como técnico-jurídicos. Por ello, se sostiene que las decisiones judiciales (de segunda instancia) son ineludibles y justamente políticas. En este sentido se califica el estudio sobre las controversias y acciones de inconstitucionalidad que tienen por objeto garantizar el federalismo y el principio de división de poderes. 
La práctica jurídica es un ejercicio de interpretación no sólo cuando los abogados interpretan documentos o leyes particulares, sino en general. El derecho así concebido es profunda y completamente político. Lo abogados y los jueces no pueden evitar la política en el sentido amplio de la teoría política. Pero el derecho no es una cuestión política personal o partidaria, y una crítica del derecho que no comprenda esta diferencia brindará un entendimiento pobre y una guía más pobre aún. (Dworkin 2012, p. 123)

Al respecto cabe señalar los tipos de argumentos basados en principios políticos, que apelan a los derechos políticos de los ciudadanos individuales -Ejemplo de ello los medicamentos para enfermos de virus de VIH-, y argumentos fundados en políticas públicas, que sostienen que una decisión dada debe promover alguna concepción de bienestar general o interés público. Considero que el enfoque correcto es que, en casos polémicos, los jueces fundan sus decisiones, y deben hacerlo, en argumentos de principios políticos y no en políticas públicas.

Se ha comentado que las reglas de elección tienen un efecto sobre quienes ocupan el encargo de ministros y de las expectativas con las que lo ejercen. Por el otro, el método por el cual los once ministros llegan a su decisión, cualquiera que ésta sea, afecta lo que se decide. Así, los ministros cuentan con responsabilidades éticas y morales en la resolución de los asuntos dado el carácter relevante de su posición, ello trae consigo un dilema ético y justo, a partir del cual un juzgador constitucional puede escoger entre por lo menos dos cursos de acción, cada uno de los cuales parece estar bien apoyado por un estándar aceptable de comportamiento.

Aunque no es una información oficial, considero resulta necesario determinar si los ministros ejercen algún credo religioso, sin son casados o no, misóginos, feministas; así como si también cuentan con alguna filiación o simpatía con respecto a algún partido político, si son homosexuales o no, incluso, si muestran alguna consideración a favor o en contra respecto a tales temas. Ejemplo de las consideraciones anteriores se rescatan de las Acciones de Inconstitucionalidad 146 y su acumulada 147/2007 y sus acumuladas por virtud del cual se decretó la constitucionalidad relativa a despenalización del aborto en el Distrito Federal y respecto al cual alguna ministra se mostró a favor de abortar, dado que era necesario preservar la belleza femenina, igual sentido lo merece la resolución a la Controversia constitucional 31/2006 respecto al cual se marcó como límites a la libertad de expresión los conceptos de 
'maricón' o 'puñal' por virtud del cual la Corte determinó que resultaban palabras ofensivas en contra de quien las profería, la Acción de inconstitucionalidad relativa al matrimonio entre personas del mismo sexo, o el Amparo en revisión 2676/2003 relativo discurso nacionalista y organicista en el sentido de señalar que la 'patria se desangra' cuando Sergio Hernán Witz construye un poema generando apología a la violencia.

\section{c) Ministros 'conservadores' y 'liberales'}

Si bien tales consideraciones no son reflejo exclusivo de una orientación política, sí permite distinguir de igual forma que también su discurso forma parte de un ejercicio de poder, del Poder Judicial de la Federación en términos constitucionales, y menciona Courtis:

Aunque el ejemplo histórico más visible de activismo judicial haya tenido una orientación progresista -refiero la justicia federal estadounidense en el periodo de la denominada Corte Warren, que durante los años sesenta y setenta protagonizó en Estados Unidos procesos tales, como el de desegregación racial, desinstitucionalización, limitación del poder de la policía y extensión de la libertad de expresión-, lo cierto es que existen ejemplos históricos de todo tipo: tribunales deferentes con poderes políticos progresistas, tribunales diferentes con poderes políticos conservadores y tribunales activistas cuya actuación se dirigió contra poderes políticos progresistas. $(2007$, p. 62)

En México, asuntos como el aborto, el matrimonio homosexual, el fuero militar y la 293/2011 han polarizado el sentido de la toma de decisiones a cargo de los Ministros y el sentido de su agrupamiento como 'conservadores' y 'liberales'. También 'internos' y 'externos'. Lo cual conforman bloques diferenciados en la aplicación de la justicia y se han agrupado sistemáticamente en razón de cada asunto calificado como relevante a saber y que implica el ejercicio de una acción política o bien la interpretación de un derecho fundamental.

El sentido de la tendencia en cuanto al agrupamiento de los ministros 'liberales' y 'conservadores' se desplego de la siguiente manera o 'bloque'. Los casos a saber, son:

1) Prohibición de discriminación por razón de salud vs eficacia de las fuerzas armadas. Análisis de las decisiones de la SCJN sobre VIH y militares 
2) Derecho a la información pública vs derecho a la vida empresarial

3) Prohibición de progresividad vs 'viabilidad financiera' del sistema de seguridad social. Análisis de la sentencia de la SCJN que declaró la validez de la 'nueva' Ley del ISSSTE

4) ¿prohibición de genocidio vs irretroactividad de la ley?.Análisis de la sentencia de la SCJN que, por mayoría de votos, declaró prescriptible el crimen de genocidio

5) Libertad personal vs Arresto de la madre o padre como medida de apremio en materia familiar. Referencia a la sentencia dictada en el juicio de amparo 210/2011, del Juzgado Sexto de Distrito del Centro Auxiliar de la Primera Región.

6) Prohibición de retroactividad vs Libertad de configuración legislativa

7) Derecho a la vida del nasciturus vs Libertad, intimidad y salud reproductiva de la madre. Referencia a los pronunciamientos de la $\mathrm{SCJN}$ y votos particulares relevantes

8) Libertad de expresión vs protección penal de símbolos nacionales (bandera). Referencia al amparo en revisión 2676/2003 y voto de minoría.

9) Equidad de género vs derecho de acceso formalmente igualitario y democrático a cargos de elección popular. Comentario a la sentencia de la SCJN dictada en las acciones de inconstitucionalidad 7/2009 y acumuladas. (Silva 2012,p. 5)

Entre 2007 y 2010, una primera coalición para resolver estuvo a cargo de los ministros: Franco, Luna, Mayagoitia y Valls calificada como 'conservadores'. Una segunda coalición se integró por los ministros Cossío, Sánchez y Silva Meza calificada como 'liberales'. Una tercera estuvo a cargo de los ministros Anguiano, Azuela y Gudiño y por último una cuarta coalición se integró por los ministros Aguilar y Zaldívar. La tercer y cuarta coalición se integró progresivamente a la primera y la segunda respectivamente, en el sentido de fallos posteriores y que implican un periodo de 2010 en adelante.

La tendencia anterior, permite establecer, por un lado, el grado de conservadurismo reflejado como consecuencia del partido político que propuso a cada ministro y que hace presumir un compromiso en cuanto a los principios propios. Recordemos que al día de hoy solo los ministros Silva Meza y Sánchez Cordero fueron propuestos por el PRI como parte de la Corte original de 1994, el resto de los ministros fueron propuestos en administraciones emanadas del PAN. Lo anterior, se fortalece con la tendencia a promover controversias constitucionales por parte de los principales partidos políticos del país, PRI 19\%, PAN 28\%, PRD 26\% y 
resto de los partidos políticos $27 \%$. Tendencia similar ocurrió al promover controversias en contra de dichos órganos políticos: PAN $30 \%$, PRI $19 \%$, PRD $0.81 \%$ y resto de partidos políticos $56.19 \%$. Cabe señalar que la tendencia es hasta 2012, fecha en que el PRI no ocupaba el cargo de Presidente de la Republica.

\section{d) La ideología en la interpretación constitucional}

El modelo neoconstitucional explica que la interpretación de la Constitución depende de la forma de entender ésta; es decir, la metodología y consecuentes exigencias interpretativas las cuales no están asociadas a la configuración neutral, objetiva y verdadera de la Constitución, sino más bien a la reconstrucción peculiar que de ella hacen los intérpretes. Se dice así que la interpretación de la Constitución ha sido 're-materializada' (Prieto 2007, p. 67) por la incorporación de normas sustantivas que tienden a limitar el ejercicio del poder mediante imperativos de justicia, que en el lenguaje jurídico reciben distintas denominaciones, a saber: valores, principios, directrices o derechos fundamentales $\mathrm{y}$, son los que producen un fuerte efecto de irradiación sobre el sistema jurídico.

Esta noción destruye el modelo paleo-positivista del derecho (Ferrajoli 2006 , p. 14), dado que las normas sustantivas no son otra cosa más que normas morales, ya que no se limitan a una validez formal normativa, ya que el escrutinio constitucional se hace también a la luz de principios de justicia. Así tenemos que la moral ya no flota sobre el derecho, por el contrario, la moral pública en la modernidad impregna la Constitución de eticidad, al constituir nada menos que el puente de unión entre el derecho y la política democrática (Nino 1994, p. 387).

En nada beneficia disociar el derecho de la moral, pues ambos encarnan expectativas de justicia al invocar que los derechos son un consenso jurídico acerca de lo permitido por hacer, más que un consenso moral de lo que debería hacerse. Así que el sistema jurídico mexicano al enfrentarse a los problemas de interpretación constitucional, se encuentra frente a problemas de principios morales (Dworkin 2009, p. $51)$, y no de hechos legales o estrategias como el enfoque profesional sugiere. De ese modo, es comprensible que hoy se hable de la Constitución mexicana desde una perspectiva axiológica, sencillamente porque los dilemas para interpretarla, en mucho, son problemas de principios morales. 


\section{CONCLUSIONES}

El año de 1994, marca un paradigma en la integración del Pleno de la Corte en México con la elección de 11 nuevos ministros, y a partir de ello la definición de una ética e ideología marcada por dos eventos particulares, el perfil individual de cada uno de los nuevos ministros calificados a partir de entonces como "internos" y 'externos', así como del proceso por virtud del cual llegan a sus determinaciones y la selección de asuntos puestos a conocimiento, circunstancia que permite a su vez establecer un segundo referente como "liberales" y "conservadores". Lo anterior, establece la consolidación a que está llamado a ejercer el Poder Judicial Federal en general y la Corte en particular como instrumento de la democracia nacional. Dicho proceso persiste con cada relevo generacional. A su vez, el proceso de elección y duración tiene un efecto sobre quienes llegan a ministras o ministros y con qué expectativas. Así, los ministros cuentan además de la constitucional con responsabilidades morales en la resolución de cada asunto dado el carácter relevante de su posición, ello trae consigo un problema en la interpretación.

La metodología, principialista o casuística en la interpretación constitucional a cargo del máximo órgano de impartición de justicia nacional, transita hacia un método consolidado en la definición del derecho, el cual de suyo ejerce una fuerte carga ideológica por parte de los propios actores.

La ideología constituye un elemento por virtud del cual es posible dar sentido a la Constitución mexicana, y a partir de entonces no solo calificarla como norma sino como principio. Ello, dado que los conflictos no son exclusivamente normativos sino de principio, es decir, los conflictos constitucionales son éticos y morales, y a partir de entonces es necesario que los interpretes de la Constitución también sean también morales, es decir éticos y justos, para consecuencia de ello se construya una teoría que no descanse exclusivamente en lo político sino en lo moral.

\section{REFERENCIAS BIBLIOGRÁFICAS}

Constitución Política de los Estados Unidos Mexicanos (1917)

Cossío, J., \& Raigosa, L. (1996). Régimen político e interpretación constitucional en México, Isonomía, 5, octubre. España: Isonomía. 
Courtis, C. (2007). Legitimidad del poder judicial ante la ciudadanía. En Rodolfo Vázquez (Com.), Corte, jueces y política. México: Fontamara.

Duncan, K. (2010). Izquierda y derecho. Ensayos de teoría jurídica critica. Argentina: Siglo XXI editores.

Dworkin, R. (2009). Los derechos en serio. España:Ariel.

Dworkin, R. (2012). Una cuestión de principios. Argentina: Siglo XXI Editores.

Ferrajoli, L. (2006). Las Garantías Constitucionales de los Derechos Fundamentales. Alicante, 29. España: Isonomía.

García, S. (2012). Deber de ponderación y principio de proporcionalidad en la práctica judicial. México: Porrúa.

La teoría constitucional de la Suprema Corte de Justicia. (2002). México: Fontamara.

Mayer-Serra, C., \& Magaloni, A. (2010). La forma es fondo: cómo se nombran y deciden los Ministros de la Suprema Corte de Justicia. 23, julio-diciembre. México: Cuestiones Constitucionales.

Nino, C.(2004).Derecho, moral y política. España:Ariel.

Prieto, L. (2007). Derecho y moral en la época del constitucionalismo jurídico, Revista Brasileira de Direito Constitucional, núm. 10. Brasil: Río de Janeiro.

Ríos, J. (2004), El surgimiento de un poder judicial efectivo en México: gobierno dividido y toma de decisiones en la SCJN, 1994-2002, México: IFE.

Rivero, P., \& Pérez, R. (2007). Ética y bioética en La construcción de la bioética. México: FCE.

Saavedra, C. (2012). Designar hoy para cosechar mañana: la importancia de la selección de los ministros de la SCJN. México: Letras libres. 